\title{
Sarcoidosis of the spleen - rare indications for splenectomy. Own experience
}

\author{
Marcin Bednarek ${ }^{1}$, Piotr Budzyński ${ }^{1}$, Andrzej Budzyński ${ }^{1}$, Sergiusz Demczuk² \\ $12^{\text {nd }}$ Department of Surgery, Jagiellonian University Medical College, Krakow, Poland \\ 2Departemnt of Pathomorphology, Jagiellonian University Medical College, Krakow, Poland
}

Videosurgery and other miniinvasive techniques 2010; 5 (3): 115-119 DOI: $10.5114 /$ wiitm.2010.16424

\begin{abstract}
The article presents two patients who underwent laparoscopic splenectomy because of splenic sarcoidosis. In one patient sarcoidosis was diagnosed based on the chest X-ray and computed tomography (CT) scans. Further imaging allowed for the diagnosis of systemic spread of the disease with bone marrow and splenic involvement. The latter location was confirmed by pathological examination after the operation. The indication for splenectomy was hypersplenism with concurrent thrombocytopenia. In the second patient, an abdominal ultrasound scan (US) showed suspicious focal lesions in the spleen. Histological examination proved it to be a rare isolated splenic form of sarcoidosis.
\end{abstract}

Key words: sarcoidosis of the spleen, laparoscopic splenectomy

\section{Introduction}

Sarcoidosis belongs to the group of diseases characterized by non-caseating epithelioid granulomas [1-3]. They consist of epithelial cells (activated macrophages) and Langhans' cells, occasionally containing Schaumann conchoid bodies and asteroid bodies $[3,4]$. The above structure is surrounded by the lymphocyte zone containing mainly T-helper lymphocytes. Inadequate excessive T-helper lymphocytes' response together with the aggregated inflammatory mediators is responsible for the presence of systemic changes [3].

The aetiology of the disease remains unclear. At its origin might lie infections, allergy, some medicines, chemicals, or autoimmune or genetic disorders [2, 5-7]. A predisposition towards sarcoidosis development was observed in subjects with HLA-B8 as well as HLA-B27 genotype [4, 7].

Sarcoidosis is localized mainly in the respiratory system, where lesions are confirmed in about $90 \%$ of cases [1, 4-7]. Extrapulmonary type is present in only around $10 \%$ of patients [1, 4-7]. The disease affects lymph nodes (78\%), liver (67\%), spleen (50\%), heart $(20 \%)$, skin $(16 \%)$, bones, kidneys (7\%) and finally eyes (6\%). The frequency of extrapulmonary lesions was determined by Peckham, who examined deceased in the course of sarcoidosis [7]. Other authors have presented similar results $[4,6]$.

Splenic involvement in the course of sarcoidosis can be asymptomatic and discovered incidentally. Giovinale et al. as well as Zia et al. emphasize that isolated splenic sarcoidosis is a rare entity [1, 5]. Among the most frequent symptoms are enlargement of the spleen (splenomegaly), sometimes accompanied by hepatomegaly (hepatosplenomegaly) $[1,8]$, discomfort and even epigastric pain $[1,5,7,8]$, rarely body mass reduction [1]. Fordice noticed that splenomegaly is present in $10 \%$ and so-called "massive splenomegaly" (above $2000 \mathrm{~g}$ ) in 3\% of patients [9]. In the laboratory tests one can notice erythrocyte sedimentation rate (ESR) elevation, hypergamma- 
globulinaemia, hyperkalaemia, increased activity of pulmonary convertase as well as cytopenia in many cellular lines $[4,5,7,8]$. In the sarcoidosis work-up the most crucial part is played by imaging [chest X-ray, computed tomography scan (CT), abdominal ultrasound scan (US), abdominal CT scan, magnetic resonance imaging $(\mathrm{MRI})][1,3-7,10]$. Tuberculosis, inflammatory response with formation of granulomas as well as neoplasms (leukaemias, lymphomas, cancer metastases) should be considered in the differential diagnosis $[1,5,10,11]$. Indications for splenectomy include splenic tumours of unknown origin, suspicion of a neoplastic process and hypersplenism in the systemic type of sarcoidosis $[1,5]$. Splenectomy can be performed in a classic way, but at present the less invasive laparoscopic approach is the gold standard $[1,5,8]$. Postoperative pathological examination confirms splenic involvement by the systemic disease or allows an alternative final diagnosis in cases of qualification of patients with splenic tumours $[1,5,8]$. In the case of hypersplenism, splenectomy leads to resolution of the excessive degradation of the morphotic blood elements. A better response to steroids following splenectomy or no need for their use in some patients was observed $[1,5,8]$.

\section{Case 1}

A 38-year-old patient was admitted to the Department in order to undergo splenectomy because of thrombocytopenia and leucopenia. Noncharacteristic symptoms, among which general asthenia and a subfebrile state were predominant, started about 8 months earlier. Sarcoidosis was diag-

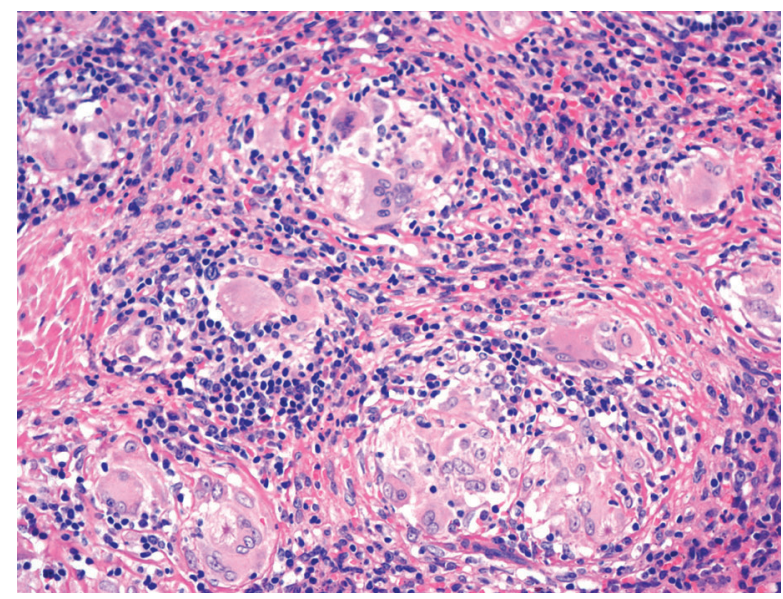

Figure 1. Splenic sarcoidosis (Magn. 200 ×; HE stain) nosed based on the chest X-ray and CT scan. The patient was treated for 6 months in the Haematology Department of the Medical University Hospital. There were focal lesions in the spleen, although it was not enlarged on the abdominal US scan prior to the surgery. Morphology results were as follows: RBC $3.87 \times 10^{6} / \mu \mathrm{l}$, WBC $6.9 \times 10^{3} / \mu \mathrm{l}$, HCT $39.8 \%$, Hb $13.8 \mathrm{~g} / \mathrm{dl}$, PLT $63 \times 10^{3} / \mu$ l. The patient was treated with steroids (methylprednisolone $80 \mathrm{mg} /$ day) with PPI cover (40 mg/day), and additionally potassium and calcium supplementation. The patient was scheduled for splenectomy, which was performed laparoscopically. There were no complications in the postoperative period and the patient was discharged on the third postoperative day. The histopathology report stated presence of irregular fibrotic foci and fine granulomatous foci consisting of histiocytes, among them giant polynuclear cells without necrosis, in the organ's parenchyma, which suggests sarcoidosis (Figures 1-3).

\section{Case 2}

A 26-year-old female patient was admitted for splenectomy because of multiple focal lesions of the spleen. The lesions were found during the abdominal US scan performed because of non-characteristic abdominal pain. Preoperative abdominal US scan showed normal size spleen with multiple oval, hypoechogenic areas $8-10 \mathrm{~mm}$ in diameter. Preoperative chest X-ray showed no pathological changes. Morphology results were as follows: RBC $4.72 \times 10^{6} / \mu \mathrm{l}$; WBC $20.49 \times 10^{3} / \mu \mathrm{l}$, HCT 37\%, Hb $12.9 \mathrm{~g} / \mathrm{dl}$, PLT 350 $\times 10^{3} / \mu \mathrm{l}$. The patient was on chronic iron supplementation. The operation was performed as a planned

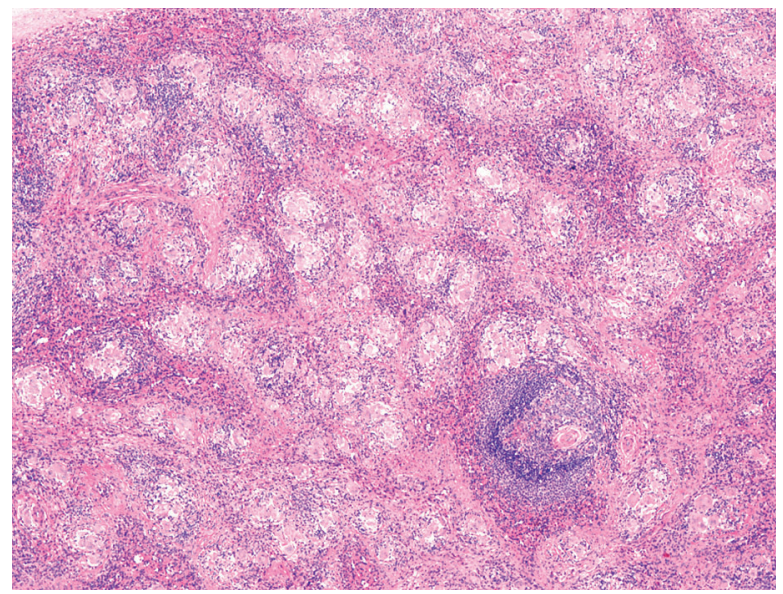

Figure 2. Splenic sarcoidosis (Magn. $100 \times$; HE stain) 
laparoscopic procedure. The postoperative period was uneventful and the patient was discharged home on the second postoperative day. Pathological examination showed fragments of spleen weighing $165 \mathrm{~g}$ with visible fine whitish nodules. Histological observation revealed focal aggregations of the epithelioid granulomas with the presence of giant polynuclear cells. In the giant polynuclear cells cytoplasm asteroid and conchoid (Schaumann) bodies were visible. Necrosis was not found in the granulomas. The histopathological picture suggests sarcoidosis.

The characteristic of patients is presented in Table I.

\section{Discussion}

Besnier-Boeck-Schaumann disease, broadly known as sarcoidosis, was first described in 1877 by Jonathan Hutchinson (1828-1913). The description referred to the skin form of the disease. In the subsequent years the knowledge on this condition has

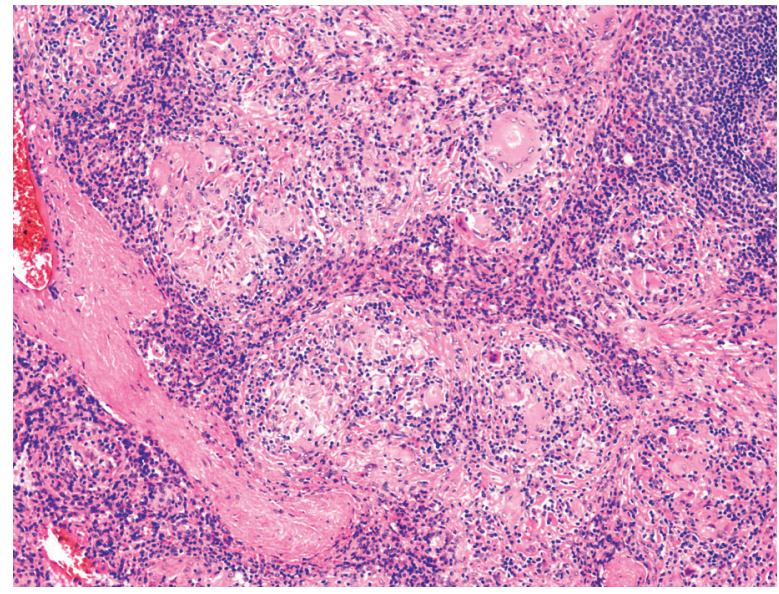

Figure 3. Splenic sarcoidosis (Magn. 100 ×; HE stain)

been deepened. Works by Caesar Peter Møller Boeck (1845-1917), Jörgen Nilsen Schaumann (1879-1953) and Ernest Henri Besnier (1831-1909) proved sar-

Table I. Characteristic of presented patients

\begin{tabular}{|c|c|c|c|}
\hline & & Patient 1 & Patient 2 \\
\hline Age [years] & & 38 & 26 \\
\hline Time since diagnosis & & 8 months & A few weeks \\
\hline \multirow[t]{2}{*}{ Laboratory tests } & WBC $\left[10^{3} / \mu l\right]$ & 6.90 & 20.49 \\
\hline & Splenic US scan & $\begin{array}{l}\text { Normal size } \\
\text { Focal changes }\end{array}$ & $\begin{array}{c}\text { Normal size } \\
\text { Multiple oval, hypoechogenic areas } \\
\text { 8-10 mm in diameter }\end{array}$ \\
\hline Indications for surgery & & $\begin{array}{l}\text { Thrombocytopenia } \\
\text { Leucopenia }\end{array}$ & Splenic focal changes \\
\hline Operative time [min] & & 100 & 120 \\
\hline Removal of drains [postoperative day] & & 1 & 1 \\
\hline Postoperative period & & Not complicated & Not complicated \\
\hline Postoperative hospitalization [days] & & 3 & 2 \\
\hline \multirow[t]{2}{*}{ Histopatological examination } & Splenic weight $[g]$ & 76 & 165 \\
\hline & Microscopic picture & $\begin{array}{c}\text { Fibrosis foci, fine foci } \\
\text { of the granulation tissue } \\
\text { consisting of the histiocytes, } \\
\text { and giant polynuclear cells }\end{array}$ & $\begin{array}{l}\text { Focal aggregations of } \\
\text { the epithelioid granulomas } \\
\text { with giant polynuclear } \\
\text { cells presence. In the giant } \\
\text { polynuclear cells cytoplasm } \\
\text { asteroid and conchoids } \\
\text { (Schumann) bodies were visible. } \\
\text { Necrosis was not found in the } \\
\text { granulomas }\end{array}$ \\
\hline
\end{tabular}

WBC - white blood cell 
coidosis to be a systemic disease that can lead to the involvement of multiple organs.

It affects young people $[2,6-8,12]$. Aladesanmi and Baughman et. al. suggest slight predominance of females $[6,12]$. The peak morbidity is between 15 and 40 years of age $[2,6-8,12]$, similar to the presented cases. The morbidity rate according to Baughman et al. is 1-40 per 100000 people [12]. Sarcoidosis is prevalent worldwide, though it is more frequently seen in Northern Europe (e.g.: Sweden 60/100 000). In the USA it affects Afro-Americans (35.5/100 000) more frequently than the white population $(5-10.9 / 100$ 000) $[3,6,7,12]$. On the other hand, reduced morbidity is observed in South America, countries of the Iberian Peninsula as well as in India $[6,12]$. Some authors consider it to be more frequent in non-smokers [3].

Primary splenic location of sarcoidosis is rarely observed. Significantly more frequently it occurs as a result of generalization of the disease, which may affect up to half of the patients [1,5]. Most frequently, patients present with atypical ailments such as asthenia, fever, cough and abdominal symptoms (discomfort, overfilling sensation or even epigastric pain). Similar non-specific symptoms occurred in both presented patients. Some forms of isolated splenic sarcoidosis can be clinically silent and can be found coincidentally during diagnostic imaging (chest X-ray or CT and abdominal US or CT scan). Those examinations played an important role in the presented patients as well. In one patient imaging allowed the diagnosis of systemic disease, whereas in the other patient, based on the incorrect picture of the spleen in the abdominal US scan the patient was qualified for splenectomy. Sensitivity and specificity of the radiological examination are limited. It can give false negative results, so in cases of an abnormal splenic picture Warshauer suggests CT or US guided biopsy [10].

Indications for splenectomy in the presented patients did not diverge from those in other conditions: hypersplenism in the form of splenomegaly, leucopenia and thrombocytopenia resistant to conservative treatment (steroids) and splenic tumours of unknown origin (suspicion of neoplastic process). In the course of sarcoidosis, the above-mentioned haematological symptoms are not frequent and the lack of a response to attempted conservative treatment gives grounds for offering surgical treatment to the patient, according to Mahévas et al. [13]. Planned laparoscopic splenectomy is currently considered the gold standard $[1,5,8,14]$ and it was performed in the presented patients. Advantages of minimally invasive surgery including minimisation of the trauma connected with "classic" access as well as the short postoperative period (2-3 days) reduce the complication rate, allow a better cosmetic effect and are a great benefit for the patients [14]. The complication rate of laparoscopic splenectomy in children is less than $13 \%$ according to Dzielicki et al. [14]. Kołomecki et al. emphasize the presence of pleural exudates as a complication of operations in the upper abdomen [15]. There were no complications observed in the presented patients. In the long-term out-patient follow-ups, improvement in the general health condition together with leucopenia and thrombocytopenia resolution was demonstrated, especially in the patient with systemic disease. Laparoscopic splenectomy allowed termination of steroid therapy and therefore reduced the risk of related complications (osteoporosis, arterial hypertension or metabolic disturbances).

\section{References}

1. Giovinale M, Fonnesu C, Soriano A, et al. Atypical sarcoidosis: case reports and review of the literature. Eur Rev Med Pharmacol Sci 2009; 13 (Suppl. 1): 37-44.

2. Moller DR. Potential etiologic agents in sarcoidosis. Proc Am Thorac Soc 2007; 4: 465-8.

3. Straszak K. Sarkoidoza - rzadka postać kliniczna. Przegl Lek 2007; 64: 531-3.

4. Van Gundy K, Sharma OP. Pathogenesis of sarcoidosis. West J Med 1987; 147: 168-74.

5. Zia H, Zemon H, Brody FJ. Laparoscopic splenectomy for isolated sarcoidosis of the spleen. J Laparoendosc Adv Surg Tech A 2005; 15: $160-2$.

6. Aladesanmi OA. Sarcoidosis: an update for the primary care physician. MedGenMed 2004; 6: 7

7. Peckham DG, Spiteri MA. Sarcoidosis. Postgrad Med J 1996; 72: 196-200.

8. Webb AK, Mitchell DN, Bradstreet CM, et al. Splenomegaly and splenectomy in sarcoidosis. J Clin Pathol 1979; 32: 1050-3.

9. Fordice J, Katras T, Jackson RE, et al. Massive splenomegaly in sarcoidosis. South Med J 1992; 85: 775-8.

10. Warshauer DM. Splenic sarcoidosis. Semin Ultrasound CT MR 2007; 28: 21-7.

11. Mohan A, Sood R, Shariff N, et al. Sarcoidosis manifesting as massive splenomegaly: a rare occurrence. Am J Med Sci 2004; 328: 170-2.

12. Baughman RP, Lower EE, du Bois RM. Sarcoidosis. Lancet 2003; 361: 1111-8. 
13. Mahévas M, Le Page L, Salle V, et al. Thrombocytopenia in sarcoidosis. Sarcoidosis Vasc Diffuse Lung Dis 2006; 23: 229-35.

14. Dzielicki J, Grabowski A, Korlacki W. Optimizing the technique of laparoscopic splenectomy in children. Videosurgery and other miniinvasive techniques 2010; 5: 19-26.

15. Kołomecki K, Cywiński J, Bartnicki J, et al. Hydrothorax as a complication of upper abdominal surgery. Videosurgery and other miniinvasive techniques 2006; 2: 59-64. 